\title{
MCIT \\ System Modeling and Management of Water Resources in Ingulets Basin
}

https://doi.org/10.31713/MCIT.2020.24

\author{
Pavlo Kovalchuk \\ Institute of Water Problems and Land Reclamation \\ National Academy of Agrarian Sciences of Ukraine \\ Kyiv, Ukraine \\ kovalchuk.pavlo.ivanovich@gmail.com
}

\section{Olena Demchuk}

National University of Water and Environmental Engineering Rivne, Ukraine

ldem1997@ukr.net

\author{
Roman Kovalenko \\ Institute of Water Problems and Land Reclamation \\ National Academy of Agrarian Sciences of Ukraine \\ Kyiv, Ukraine \\ romchik89@ukr.net \\ Volodymyr Kovalchuk \\ Institute of Water Problems and Land Reclamation \\ National Academy of Agrarian Sciences of Ukraine \\ Kyiv, Ukraine \\ volokovalchuk@gmail.com
}

\author{
Hanna Balykhina \\ National Academy of Agrarian Sciences of Ukraine \\ Kyiv, Ukraine \\ maslova-anna@ukr.net
}

\begin{abstract}
Mathematical models have been developed for managing the water resources of the Ingulets River in accordance with the requirements of the $\mathbf{E U}$ Water Framework Directive on the establishment of cost-effective water use with ensuring good or excellent ecological river status. The structural and functional diagram of the system model includes the subsystems: water supply by the Dnipro-Ingulets canal; flushing the Ingulets River from the Karachunivske reservoir and displacing the saline prism into the Dnipro River; environmental safety when discharging pollution into the river Ingulets; water supply for irrigation in the Ingulets irrigation system, prevention of soil salinization. Integrated management is carried out by subsystems, by types of management and by a system of criteria. A system of economic and environmental criteria for evaluating integrated management by the basin principle has been developed. Simulation of scenarios based on operational management is carried out. Scenarios are optimized according to the Pareto principle. An example of evaluating the effectiveness of the proposed control system and its comparison with the existing regulations for flushing the Ingulets River is given.
\end{abstract}

Keywords - balance differential equations; water exchange; integrated management; evaluation criteria; river flushing; system model.

\section{INTRODUCTION}

River basin, as a complex system, belongs to the most important objects in environmental systems management. In [1, 2], the necessity of introducing the basin management principle was substantiated, in which the river basin acts as the main unit of management and which is "a system with established ecological, social and economic ties" [3]. The peculiarity of such systems is that they describe objects that have fundamentally new properties, such as hierarchy, structural organization, adaptability, controllability in conditions of uncertainty and risk, multicriteria in assessing functioning. It means that the management of this system cannot be carried out by separate analytical or statistical methods, it must be considered as an integrated socio-ecological-economic system [4], in which the coordination of management decisions is achieved by applying the system management methodology [5]. In accordance with the EU Directive [6], the development of river basin management plans ensures the establishment of cost-effective water use with achieving good or excellent ecological status of the rivers.

Therefore, the urgent task is to develop mathematical models for managing the water resources of the Ingulets river basin, according to which scenario modeling of technological solutions, their assessment and optimization of economic criteria for effective water use with environmental restrictions are carried.

\section{METHODOLOGY AND MODELS}

\section{A. Structurally Functional Approach}

System modeling, as a toolkit, allows you to apply a structurally functional approach for integrated river basin management. However, each basin has its own specifics and subsystems, which should be reflected in the integrated management model (Fig. 1). The structural and functional diagram of the Ingulets river basin system model was developed, structural subsystems were identified, such as: I the water supply subsystem by the Dnipro-Ingulets canal, water supply along the river channel and the filling of the 


\section{Modeling, control and information technologies -2020}

Karachunivske reservoir; II - a subsystem for flushing the Ingulets river from the Karachunivske reservoir with the displacement of the saline prism into the Dnipro River; III - a subsystem of environmental safety (when discharging effluents by polluting enterprises into the Ingulets river); IV - a subsystem of water supply for irrigation in the Ingulets irrigation system, prevention of soil salinization.

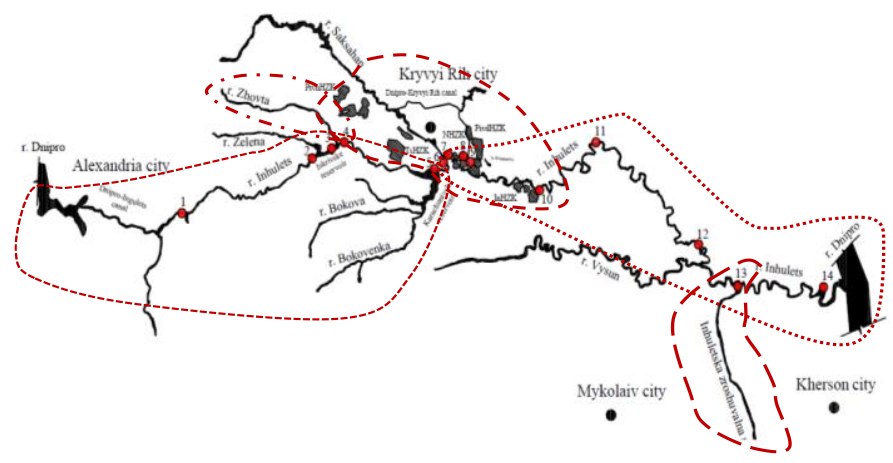

Figure 1. Structural diagram of the Ingulets river basin according to the selected subsystems.

Functional subsystems include: formalization of management criteria, an operational management and monitoring system, balance models of water and pollution movement; scenario modeling and selection of optimal variants of the control structure according to the Pareto principle [7].

\section{B. River Basin Management Criteria}

Technological criterion $F_{1}(x, t)$ determines the maintenance of the water level in the reservoir within the specified limits:

$$
H_{2}(t) \leq F_{1}(x, t) \leq H_{1}(t),
$$

where $H_{1}(t), H_{2}(t)$ are the lower and upper water levels during its using.

Economic criteria $F_{2 i}(T)$ are mathematically defined as the total water consumption for period $\mathrm{T}$ for supplying of water consumers or for flushing of the river:

$$
F_{2 i}(T)=\int_{0}^{T} Q_{i}\left(x_{i}(t), U_{i}(t) d t, i=1, \ldots, n,\right.
$$

where $Q_{i}$ is the nonlinear function of water flow for the object $x_{i}(t) \in X$ and control $U_{i}(t) \in U$ at period $t \in(0 ; T)$.

Environmental criterion $F_{31}(x(t), Q(t))$ expresses the degree of risk of pollution export to the river floodplain at some point $\mathrm{x}(\mathrm{t})$ at flow rates $\mathrm{Q}(\mathrm{t})$ at time $\mathrm{t}$ :

$$
F_{31}(x(t), Q(t))=R(x(t), Q(t))
$$

where $\mathrm{R}$ is a certain function of the risk measure, which depends on the flow of water from the reservoir $\mathrm{Q}(\mathrm{t})$. Environmental releases $Q(t) \geq C(x, t)$ are also formalized, which exceed a certain amount of river flow. For river rehabilitation the water discharge during washing is determined, which ensures the non-return of the saline prism at the water intake. At the same time, environmental goals are also taken into account, set as restrictions on water quality or as criteria for achieving a good ecological river status:

$$
F_{4 j}(x, t) \leq C_{j}, j=1, \ldots, k,
$$

where $F_{4 j}(x, t)$ are environmental criteria, $C_{j}$ are restrictions on water quality indicators according to current standards at the moments $t \in(0 ; T)$ at measurement points $\mathrm{X}$.

\section{River Basin Management System}

In the water supply subsystem of the Dnipro-Ingulets canal, the water level is controlled and the Karachunivske reservoir is filled according to the criterion of supporting water levels (1). Flushing is necessary to displace the salt water prism into the Dnipro River, which is formed as a result of pollution by enterprises between the dam of the reservoir and the Andriyivka village (Fig. 1). The result of flushing should be the achievement of a good ecological river status according to the criteria (3), (4) and the supply of water of satisfactory quality to the Ingulets irrigation system.

River flushing is carried out by displacing the prism of mineralized waters without significant mixing. In the combined control system [8-9] (Fig. 2), a positional component is set an open line for planning the sequence of impulses in time with their discharges from the reservoir and is adjusted in the control process. Making decisions about the next impulse is taken according to the function that evaluates the control actions based on the input and output values at the same time, that is, feedback is used:

$$
Q\left(x, t_{n+1}\right)=F\left(V_{i}\left(t_{n}\right), S_{i}\left(t_{n}\right), V_{j}\left(t_{n}\right), S_{j}\left(t_{n}\right), Q\left(x, t_{n}\right)\right)
$$

where $Q\left(x, t_{n+1}\right)$ is the expense (impulse) at the next $(n+1)$ time moment; $V_{j}, S_{j}$ are chlorine concentrations in the upper and lower layers at the point in front of the water intake; $V_{i}, S_{i}$ are concentrations in the upper and lower layers at the water intake point; $Q\left(x, t_{n}\right)$ is the discharge at the previous time from the reservoir; $F$ is a function that determines the decisionmaking algorithm; $R$ is a reservoir; $q_{1}, q_{2}, \ldots, q_{n}$ are uncontrolled water flows from diffuse and point sources; $P_{1}, P_{2}$ are concentration values at sampling points in front of the water intake and at the main pumping station; WIP is water intake point for irrigation system or for industrial needs; SPMW is the state of the prism of mineralized waters; DMU is decision making unit; $\mathrm{A}$ is positional component of the combined control system; MDIC is management of the Dnipro-Ingulets canal.

The Ingulets river basin management system provides for the creation of a control center for water intake at the Ingulets irrigation system. There is a need for the rapid collection and transmission of data based on the use of telecommunication technologies [10]. To implement the DMU algorithm, the following data are used: water supply by the Dnipro-Ingulets canal, water level in the Karachunivske reservoir and water flow from the reservoir, the quality of water resources at the 


\section{Modeling, control and information technologies -2020}

Andriyivka observation point and at the intake to the Ingulets irrigation system, the state of the saline water prism.

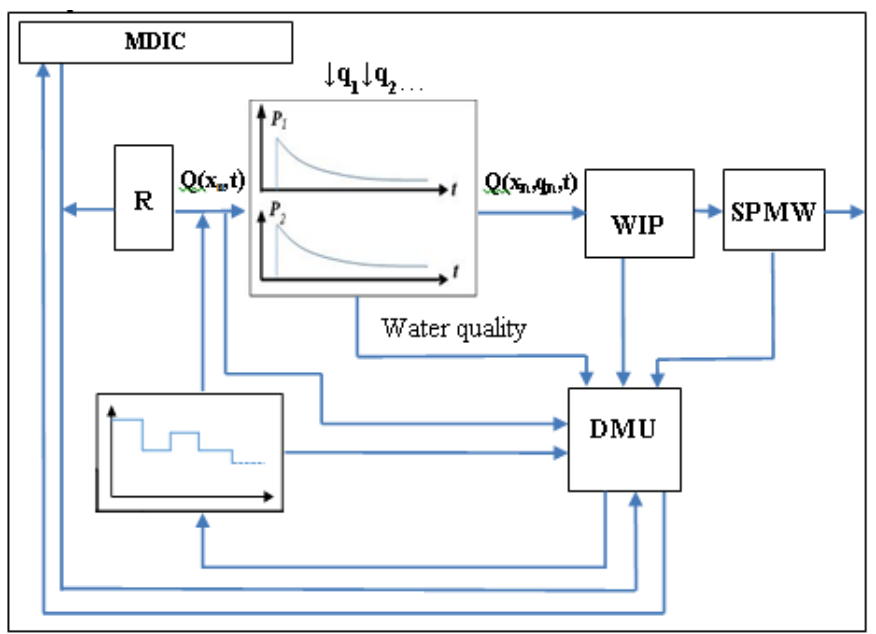

Figure 2. The scheme of the combined control system for the Ingulets river by pulse method.

When choosing river basin management scenarios, an integrated approach is used for environmental and economic goals [8]. The choice of structure options in the management system involves the optimization of economic goals:

$$
\left\{\int_{0}^{T} F_{1}(X(t+1), U(t)) d t, \ldots, \int_{0}^{T} F_{n}(X(t+1), U(t)) d t\right\} \rightarrow \max ,(6)
$$

where $F_{1}, \ldots, F_{n}$ are economic criteria, defined as the total cost over the $\mathrm{T}$ interval, to evaluate the quantity and quality of water resources; $\mathrm{X}(\mathrm{t})$ and $\mathrm{U}(\mathrm{t})$ are the system and control states at time moment $\mathrm{t}$, respectively.

In addition, at the control interval $\mathrm{T}$, environmental goals are taken into accounts that are set as limitations or as criteria for achieving a good ecological state of the river basin:

$$
\left\{\begin{array}{l}
F_{n+1}(X(t+1), U(t)) \leq C_{n+1}(t) ; \\
F_{p}(X(t+1), U(t)) \leq C_{p}(t),
\end{array}\right.
$$

where $F_{n+1}, F_{p}$ are ecological criteria, $C_{n+1}(t+1), C_{p}(t)$ are constraints at time moment $t \epsilon[0 ; \mathrm{T}]$ to achieve good or excellent ecological status.

\section{Modeling of Water Movement and Pollution Propagation}

For simulation of control scenarios, balance models based on the equation of dynamics and conservation of water masses and pollutants are proposed. Water exchange in the reservoir occurs so [10] that part of the contaminated water is displaced by the water flow from the channel:

$$
W_{i}^{n+1}=W_{i}^{n}+q_{i}^{n}-p_{i}^{n}-E_{i}^{n}, n=1, \ldots, N,
$$

where $W_{i}^{n+1}, W_{i}^{n}$ are volumes of water resources in the reservoir at the $(\mathrm{n}+1)$ and $\mathrm{n}$-th time moment in the $\mathrm{i}$-th cell; $q_{i}^{n}$ is the volume of water resources coming from the channel and the inflow into the reservoir; $p_{i}^{n}$ is the volume of water taken from the reservoir; $\mathrm{i}$ is the number of cells; $E_{i}^{n}$ is the water evaporation.

The concentration of the substance at the n-th time moment in the i-th cell as a result of mixing is calculated by the formula:

$$
U_{i}^{n+1}=\frac{W_{i}^{n} U_{i}^{n}+q_{i}^{n} C_{i}^{n}-p_{i}^{n} S_{i}^{n}}{W_{i}^{n+1}}, n=1, \ldots, N,
$$

where $W_{i}^{n} U_{i}^{n}$ is the volume of water resources $W_{i}^{n}$ with a concentration of $U_{i}^{n}$ in the $\mathrm{i}$-th cell at the n-th time moment; $q_{i}^{n} C_{i}^{n}$ is the volume of water resources $q_{i}^{n}$ coming from the channel to the reservoir with a concentration of $C_{i}^{n}$ in the i-th cell at the n-th time moment; $p_{i}^{n} S_{i}^{n}$ is the volume of water resources $p_{i}^{n}$ taken from the reservoir with the concentration of $S_{i}^{n}$ in the i-th cell at the n-th time moment.

As a result of flushing [9], the processes of displacing contaminated water and the processes of mixing the upper water layer with the lower one interact. We consider a twolayer balance difference model, which describes the movement of water in the upper layer of the stream (where significant speed) and the dynamics of the flow in the bottom layer (where the movement of a slowly changing flow occurs) [8].

\section{MODELING THE MANAGEMENT OF THE INGULETS RIVER BASIN}

To implement a systematic model of water resources management, the Ingulets River Basin was selected (Fig. 1). The water level in the Karachunivske reservoir (Fig. 1) is maintained by replenishing water from the Dnipro-Ingulets canal and the natural river flow in accordance with criterion (1). The water quality in the reservoir is satisfactory; water is taken for drinking needs of the city of Kriviy Rig and flushing the river.

A scenario analysis of the options for integrated river flushing control was carried out according to a system of criteria (Fig. 3, b). The optimal scenario III was selected according to the Pareto principle, which provides for the operational management of the river flushing based on three pulses. Feedback is carried out on the content of toxic ions of anion-chlorine (Fig. 4) to prevent the negative process of the soil salinization under irrigation conditions. In this scenario, the environmental component of the flushing is improved so that within 7 days a pulse is supplied with an increasing flow rate from 5 to $20 \mathrm{~m}^{3} / \mathrm{s}$. It ensures that the channel is flushed without an artificial flood entering the backwater. At the same time, a flushing pulse plan is set, which is adjusted by the 


\section{Modeling, control and information technologies -2020}

feedback loop in the combined control system according to the results of water quality measurements at Andriyivka observation point and at the point of its selection for the Ingulets irrigation system. The management scenario takes into account the average ten-day volumes of water intakes for irrigation.

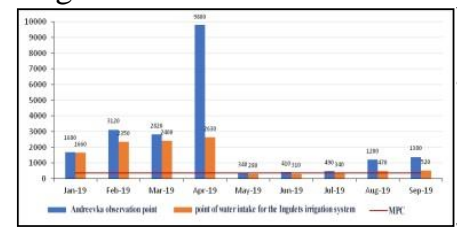

a)

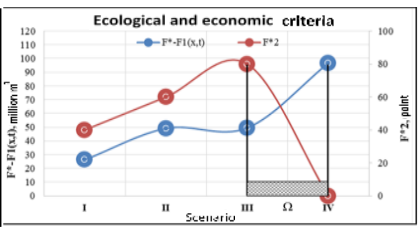

b)
Figure 3. Water quality according to the anion-chlorine indicator before water intake (Andriyivka observation point) and when taken to the Ingulets irrigation system in 2019 (a), the principle of choosing Pareto optimal control options (b).

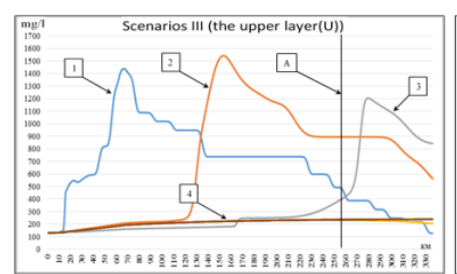

a)

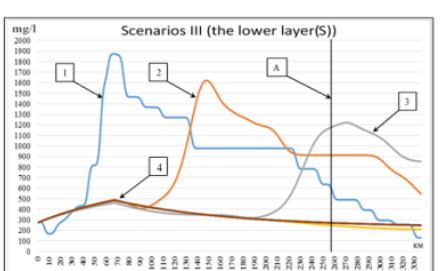

b)
Figure 4. Dynamics of Cl- pollution in the upper (a), lower (b) layers during the flushing process under the scenario of III at various points in time: 1 - the first day; 2 - the seventh day; 3 - the fifteenth day; 4 - 30-90th days (steady state).

Compared to the non-feedback flushing method existing in 2019 in the combined control system, water quality remains within the MPC. According to the economic criterion, the proposed combined management system uses only 160 million cubic meters water for flushing the river, and the existing flushing system is much larger - 190 million cubic meters (Fig. 5). It is recommended to increase the washing period from April 1 to September 15. A comparative analysis of the two flushing methods showed the great effectiveness of the method with feedback on environmental criteria and the magnitude of the water intakes for flushing and irrigation (Fig. 5).

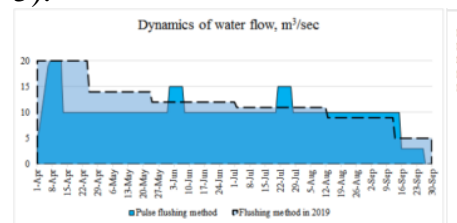

a)

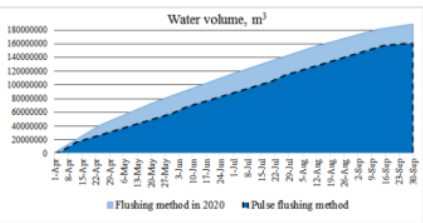

b)
Figure 5. Dynamics of water flow (a) and water volume (b) in different methods of flushing control.

\section{CONCLUSIONS}

The system model allows for the most complete implementation of integrated water resources management according to the basin principle. The structural and functional diagram of the model involves the division of the Ingulets river basin into subsystems, the interconnection between which provides a holistic consideration of such a system for making managerial decisions. A formalized system of criteria for making managerial decisions allows to maintain water balance in reservoirs according to technological indicators, to control water flow for flushing the river, to conduct environmental releases and to maintain satisfactory water quality at water intake points according to environmental ones and to evaluate and select optimal management scenarios for economic criteria.

The scenario analysis model allows you to choose the most effective river flushing option for environmental and economic criteria. The pulse method in the control system is a toolkit for implementing the most effective scenario according to economic criteria, ensuring a good ecological condition and river rehabilitation.

It is recommended to use an integrated approach to select a water management structure in a river basin according to a system of technological, economic and environmental criteria, to choose a river flushing management system based on a scenario ecosystem analysis of options, and to determine the best option according to the Pareto principle.

A comparative analysis of the proposed feedback flushing method in the combined control system, unlike the existing flushing method in 2019, showed a saving of 30 million cubic meters of water and the ability to provide the required quality of water resources (not exceeding the MPC) during the growing season.

\section{REFERENCES}

[1] V. Dukhovny, V. Sokolov, H. Manthrithilake, "Integrated Water Resources Management: Putting Good Theory into Real Practice. Central Asian Experience". SIC ICWC, Tashkent, 2009.

[2] V. Stashuk, A. Yatsik, "Ukraine on a hat before the pooling principle of managing water resources". Vodnoe gospodarstvo Ukrainy, no. 4, 2007, pp. 6-10.

[3] O.M. Klimchik, T.V. Pinkina, A.A. Pinkin, "Implementation of Integrated Water Resources Management System by Basin Principle”. Scientific Journal "ScienceRise", no. 4 (45), 2018, pp. 36-40.

[4] P.I. Kovalchuk, V.P. Kovalchuk, "System management as a development of integrated water management of the reclaimed territories". Journal of NUWEE. N.3 (71), 2015, pp. 19-23.

[5] M. Zgurovsky, N. Pankratova, "Basics of system analysis". BHV, Kyiv, 2002, 544 p.

[6] Directive 2000/60/EC of the European Parliament and of the Council of 23 October 2000 establishing a framework for Community action in the field of water policy // Official Journal of the European Communities. 22.12.2000, ENL327/1

[7] V. Podinovsky, V. Noghin, "Pareto optimal solution for multicriterion problems”. Nauka, Moscow, 1982, 253 p.

[8] Pavlo Kovalchuk, Hanna Balykhina, Roman Kovalenko, Olena Demchuk, Viacheslav Rozhon,. "Information technology of the system control of water use within river basins. Advances in Computer Science for Engineering and Education, 123-132. DOI: https://doi.org/10.1007/978-3-319-91008-6_13

[9] P.I Kovalchuk, T.V.Matyash, V.P. Kovalchuk, O.S. Demchuk, G.A. Balikhina, A.V. Gerus, N.V. Pendak, "System modeling and management of water and land use". Monograph. Kyiv, Agrarian Science, 2019, 608 p.

[10] P. Kovalchuk, V.Rozhko, V. Kovalchuk, H. Balykhina, O. Demchuk, "Optimization of integrated water exchange management technologies in territorial systems for conditions of sustainable development". In 2019 IEEE 14th International Conference on Computer Sciences and Information Technologies (CSIT), Vol. 1, pp. 80-83. 